\title{
Assessment of visual impact due to surface mining with the Lvi method
}

\author{
Dentoni V., Grosso B. and Massacci G. \\ Department of Civil and Environmental Engineering and Architecture - University of Cagliari, Via Marengo \\ 2, Cagliari, Italy
}

\begin{abstract}
Surface mining and quarrying typically generate a number of environmental concerns among which landscape alteration is one of the most significant. Although landscape and visual impact does not directly affect public health, it usually generates a negative reaction among potential observers, sometimes influencing the socioeconomic development of the surrounding impact territory. The landscape and visual impact assessment involves individual perceptions, aesthetic tastes and visual comprehension; however, some aspects of landscape modification can be objectively measured in order to quantify the magnitude of change. The article summarizes the results of previous studies focused on the implementation of the Lvi (Level of Visual Impact) method to a variety of cases within the European territory and discusses the adequacy of the method in providing an objective estimation of the visual damage produced by surface mining and quarrying. The visual impact indicator Lvi takes into account two parameters among those physically measurable: the extent of the visible alteration and the chromatic contrast between the color of the bare rock and that of the surrounding landscape. Both parameters can be quantified by processing one or more digital images taken from the most significant viewpoints (public roads, towns, villages, touristic sites, etc.). The article also includes the results of a recent study where the use of a global impact factor LVI to be associated to a given route has been proposed, in order to account for the variability of the visual impact along the route. Other studies proved the visual impact indicator Lvi to be significantly correlated with the subjective perception of potential observers, the results of a test carried out in the University of Cagliari are briefly reported in this article. Some critical aspects regarding the variability of the results on the basis of the shooting conditions (type of camera, season and time of the day, etc.) are discussed, as well as the possibility of developing the assessment procedure as to include the estimate of the ante-operam quality of the impact territory under exam and the number and type of people who are likely to observe the landscape modification.
\end{abstract}

\section{INTRODUCTION}

Surface mining, quarrying and civil engineering works involving excavation generate a number of environmental impacts among which landscape alteration can be considered one of the most significant. Although landscape alteration does not directly affect public health it usually generates a negative reaction within potential observers and in some cases strongly influences the socio-economic development of the surrounding territory.

A recent study proved the presence of active or non-reclaimed mines to be a fundamental contributor to the negative perception of the whole landscape (Svobodova et al. 2012). In particular, landscape alteration might be perceived very negatively by observers who do not live in the mining or post-mining area and are not prepared to accept incongruities in the natural landscape. Local residents, on the other hand, tend to justify landscape modifications due to industrial activities, because they associate such evidences with a source of wealth and occupational opportunities (Dentoni \& Massacci 2013).

Differences in the residents' and non-residents' visual perception were observed in a recent investigation (Sklenicka \& Molnarova 2010) aimed at comparing the respondents' judgment with reference to different habitats adopted for post-mining reclamation. The investigation proved that older people who live in post mining-areas prefer habitats with evidences of productive functions while younger and more educated respondents who live outside the post-mining areas prefer habitats with ecological, aesthetic and recreational characters.

As a matter of fact, the assessment of landscape and visual impact due to surface excavation involves individual perceptions, aesthetic tastes and visual comprehension (Nicholson 1995). However, some 
aspects of landscape modifications can be objectively measured in order to quantify the magnitude of change. The Lvi parameter proposed here integrates two objective elements of landscape modifications: the extent of the visible alteration and the chromatic contrast between the color of the bare rock exposed by excavation and the colors of the surrounding natural landscape.

The article reports the results of the application of the Lvi (Level of Visual Impact) indicator to a variety of cases within the European territory and discusses the adequacy of the method in providing an objective estimation of the visual damage produced by surface mining and quarrying.

\subsection{Extent of visible land alteration}

Considering an observation point $\mathrm{P}$, it is possible to assign an objective value to the extent of the visible alteration by considering the solid angle $\Omega_{\mathrm{v}}$ subtended by the altered area, according to equation (1):

$\Omega_{v}=\iint_{S v} \frac{\hat{\mathrm{n}} \cdot d a}{r^{2}}$

where $S v$ is the visible altered surface, $d a$ is the differential area (i.e. the area of an infinitesimal surface element of $S v$ ), $\hat{\mathrm{n}}$ is the unit vector along the direction from $\mathrm{P}$ to $d a$ and $r$ is the distance from $\mathrm{P}$ to $d a$. Equation (1) may be simply rewritten as:

$\Omega_{v}=\frac{A_{v}}{r^{2}}$

where $A_{v}$ is the projection of the altered surface onto a sphere centred on $\mathrm{P}$ with radius $r_{s}$ (Figure 1). Since in practical cases the solid angle takes values ranging from 0 to a few tens of thousandths of sr, the use of a logarithmic function has been suggested (Pinzari \& Re 1990). According to the method discussed here the geometrical aspect of the visible alteration is defined by Equation (3), where $\Omega_{\mathrm{v}}$ is divided by a chosen reference value $\Omega_{0}$.

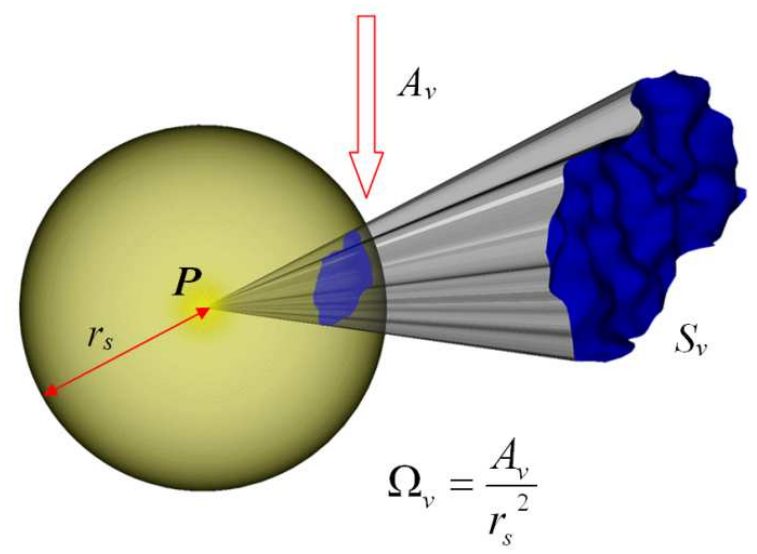

Figure 1. Extent of the visible alteration defined by the solid angle $\Omega v$ from the viewpoint $\mathrm{P}$
$L_{v}=10 \cdot \lg \frac{\Omega_{v}}{\Omega_{0}}$

It's worth noting that the standard definition of normal visual acuity (1.0 or 20/20 vision) is the ability to distinguish alternating black and white lines separated by a visual angle of one minute arc, a smaller angle would make the pattern to appear as a mass of solid gray. In equation (3) $\Omega_{0}$ is the solid angle corresponding to two plane visual angles of one minute along two perpendicular directions; the resulting value $\Omega_{0}=8.46 \cdot 10^{-8}$ sr can be considered as the visibility threshold under maximum contrast conditions in a black and white space (Dentoni et al. 2004). As regards the maximum measurable value of the visibility level, it has to be considered that the human visual field embraces $180^{\circ}$ of azimuth angle and $110^{\circ}$ of zenith angle, accounting for the eye and head mobility: the two plane angles correspond to a solid angle of 5,14 sr and a maximum visibility level of $77,8 \mathrm{~dB}$.

The solid angle $\Omega_{\mathrm{v}}$ subtended by the altered area can be easily calculated from the digital image of the alteration taken from an observation point $\mathrm{P}$, according to equation (4):

$\Omega_{\mathrm{v}}=\Omega_{p} \cdot \frac{N_{a}}{N_{p}}$

where $\Omega_{\mathrm{p}}$ is the solid angle subtended by the entire picture, $\mathrm{N}_{\mathrm{a}}$ and $\mathrm{N}_{\mathrm{p}}$ are respectively the number of pixels representing the altered area and the total number of pixels of the picture. $\Omega_{p}$ is easily determined, provided that the focal length and the CCD (Charged Coupled Device) area are known (Figure 2).

\subsection{Degree of chromatic contrast}

The chromatic contrast between the bare rock and the surrounding area can be calculated with reference to a specific color space (RGB, Luv, Lab etc.).

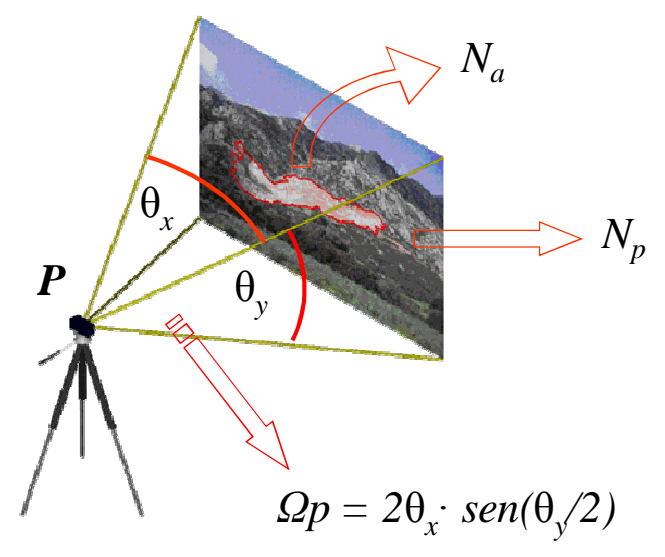

Figure 2. Calculation of the solid angle $\Omega_{\mathrm{v}}$ from a digital image taken from the viewpoint $\mathrm{P}$ 
Common digital cameras normally use the RGB coordinates system, however, previous studies proved the CIE Luv and the CIE Lab coordinates to be more satisfactory than the RGB system in representing a perceptually uniform space (i.e.: the chromatic distance of two given points better represents the chromatic contrast perceived by the human eye). The conversion of the RGB coordinates into CIE Luv or the CIE Lab coordinates can be carried out using the appropriate algorithm.

It has to be considered that the use of the CIE Lab color system is prevalent compared to the CIE Luv system; moreover, the CIE Lab color space has been applied to estimate the perception of chromatic differences in other visual impact related issues (Bishop 1997). Nonetheless, some of the results of previous studies reported in the following part of this article are based on the use of the CIE Luv system.

No matter what the color space in use, the chromatic contrast between two given points can be evaluated as the Euclidean distance $\Delta E$ defined by equation (5):

$$
\Delta E=\sqrt{\Delta x^{2}+\Delta y^{2}+\Delta z^{2}}
$$

where $\Delta x, \Delta y$ and $\Delta z$ are the differences between the values of the three chromatic coordinates of the two points in the color space under consideration (RGB, Luv, Lab etc.).

\subsection{The Lvi indicator}

The two parameters $\Omega_{\mathrm{v}}$ and $\Delta E_{\mu}$ indicating the landscape modification are integrated in the visual impact indicator $L v i$, according to equation (6):

$L_{v i}=10 \cdot \log \left(\frac{\Delta E_{\mu}}{\Delta E_{B W}} \cdot \frac{\Omega_{v}}{\Omega_{0}}\right)$

where $\Delta E_{\mu}$ is the mean value of the Euclidean distance from the mean color of the bare rock and the color of each pixel included in a comparison surface immediately around the excavation perimeter. In fact, the application of $L v i$ is based on the assumption that the chromatic contrast produced by any modification mainly depends on the chromatic characteristics at the boundaries of the excavation. Therefore one or more comparison surfaces need to be selected in order to quantify the degree of chromatic contrast (Dentoni et al. 2004). Recent studies confirmed that people tend to compare the exposed excavation with the adjacent area, instead that with the sky or with more distant areas (Menegaki et al. 2014).

Figure 3 shows the selection of two different comparison surfaces around a limestone quarry seen from a main road in the Sardinian countryside: considering the variable pattern of the vegetation cover, two different comparison areas were selected.

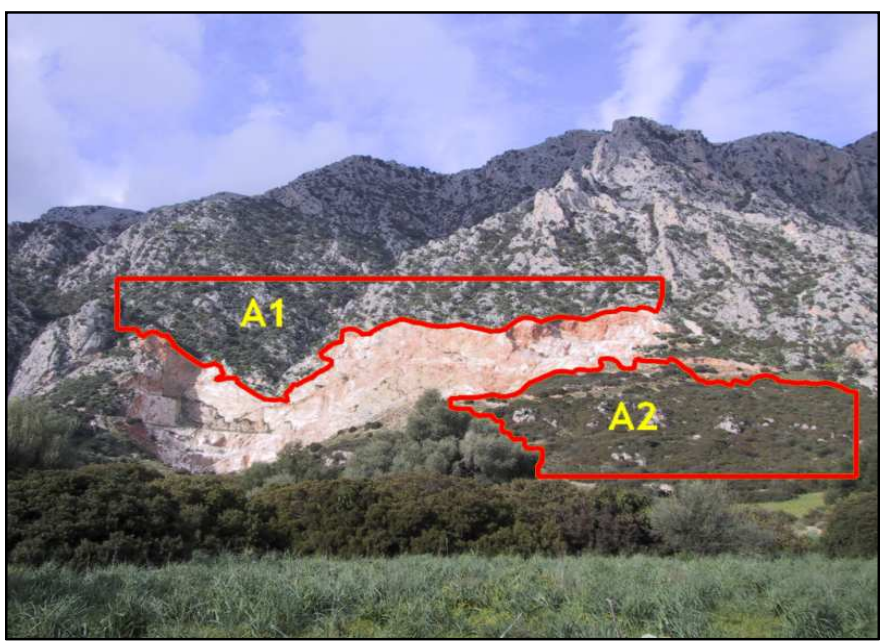

Figure 3: Selection of two different comparison surfaces (A1 and A2) around a limestone quarry (Dentoni et al. 2004)

In this case, the quarry face visible from the road is of a light color, but red predominates. The hillside where the quarry has been cut is characterized by rock outcrops alternating with typical Mediterranean bush (surface A1) whereas lower down the hillside rock outcrops are few and far between (surface A2).

The mean value $\Delta E \mu$ calculated for each of the two selected surfaces is divided by the Euclidean distance $\Delta E_{B W}$ between black and white, in order to obtain the mean standard chromatic contrast $\Delta E \mu / \Delta E_{B W}$. The value of $\Delta E_{B W}$ is 100 , both in CIE Lab color space and in the CIE Luv color space.

As a first example of the $L v i$ application, the results of the elaboration for the quarry in Figure 3 are reported in Table1 and include: the solid angle subtended by the quarry's face, the mean chromatic contrast for the two comparison surfaces in the Luv color space, the standard deviation of the chromatic contrast and the resulting visual impact level $L v i$.

The histograms of figures 4 and 5 show the frequency distribution of the standard chromatic distance $\Delta E / \Delta E_{B W}$ for $A 1$ and $A 2$. As regards $A 1$, it can be seen from the picture that the area includes a large proportion of light colored rock outcrops that contrast with the dark vegetation: the frequency distribution of $\Delta E / \Delta E_{B W}$ (chromatic distances from the mean color of the bare rock and each pixel included in the selected comparison surface) is therefore bimodal and scattered, with a mean value $\Delta E \mu / \Delta E_{B W}$ of 0.354 and standard deviation $\sigma_{\triangle E \mu}$ of 0.121 . The main mode $\left(\Delta E / \Delta E_{B W}=0.388\right)$ corresponds to the predominating contrast between the vegetation and the quarry, whereas the secondary mode $\left(\Delta E / \Delta E_{B W}=\right.$ 0.20 approx.) refers to the limited contrast between the quarry and the natural rock outcrops.

Table 1. Visual impact parameters for the case in figure 3 (Dentoni et al. 2004)

\begin{tabular}{ccccc}
\hline Case & $\Omega_{\mathrm{v}}[\mathrm{sr}]$ & $\Delta E \mu / \Delta E_{B W}$ & $\sigma_{\Delta E \mu}$ & Lvi $[\mathrm{dB}]$ \\
\hline $\mathrm{A} 1$ & 0.0474 & 0.354 & 0.121 & 53.0 \\
\hline $\mathrm{A} 2$ & 0.0474 & 0.378 & 0.091 & 53.3 \\
\hline
\end{tabular}




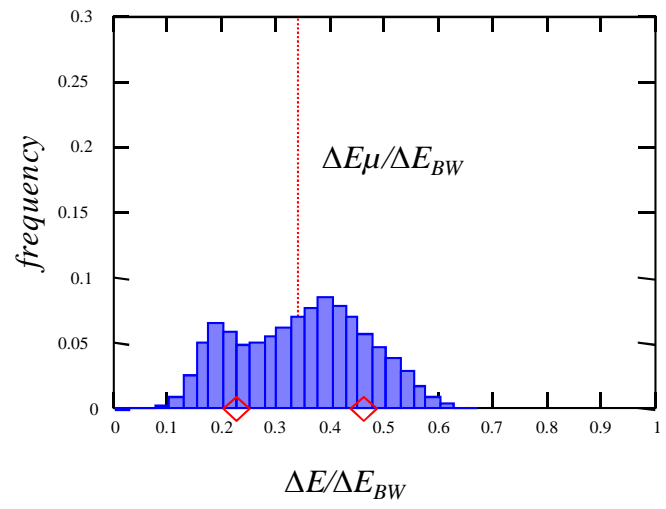

Figure 4: Frequency distribution of $\Delta E / \Delta E_{B W}$ for A1 (Dentoni et al. 2004)

Very few rock outcrops exist in the selected area A2; the frequency distribution of $\Delta E / \Delta E_{B W}$ is therefore unimodal, with a slightly higher mean value than A1 $\left(\Delta E \mu / \Delta E_{B W}=0.378\right)$ and a relatively limited dispersion (std. dev. $\sigma_{\triangle E \mu}=0.091$ ).

The application of the Lvi method in the case under exam highlights the sensitivity of $L v i$ to the choice of the comparison area, even though the difference between the two cases (A1 and A2) is negligible $(0.3 \mathrm{~dB})$.

It's worth noting that in the variety of cases considered in previous studies by the authors of this article $L v i$ was found in the range between $25,6 \mathrm{~dB}$ and $53,5 \mathrm{~dB}$; so that the quarry in Figure 3 must be considered one of the most critical case studies taken into consideration.

In addition, the method make it possible to evaluate the cumulative visual impact arising from two or more quarries which are simultaneously visible from the same viewpoint (Dentoni \& Massacci 2013). However, it has to be considered that the proposed indicator $L v i$ does not account for the shape of the visible excavation and for the modification of the mountains profile.

\subsection{Variability of visual impact along a given route}

A further development of the research regarding the assessment of visual impact due to surface mining and quarrying has been discussed in a recent article where the possibility of calculating a global impact level $L V I$ to be associated to a given route has been proposed (Dentoni \& Massacci 2012).

In order to account for the variability of the visual impact caused by two mines, currently exploited for the production of feldspar (case $a$ ) and talc (case b), along the same public road, the use of equation (7) has been suggested:

$$
L V I=10 \cdot \lg \left(\frac{1}{D} \cdot \sum_{j=1}^{n} 10^{\frac{L v i_{J}}{10}} \cdot d j\right)
$$

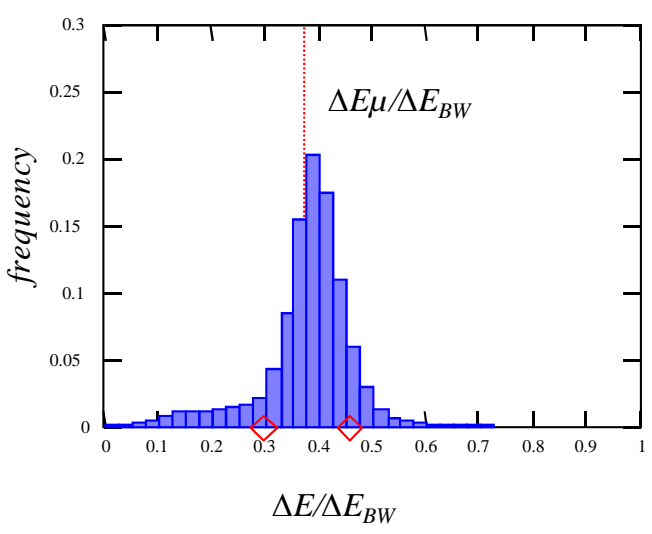

Figure 5: Frequency distribution of $\Delta E / \Delta E_{B W}$ for A2 (Dentoni et al. 2004)

where $D$ is the length of the road from where the alteration is visible; $n$ represents the number of selected viewpoints; $L v i_{\mathrm{j}}$ is the level of visual impact at the $-\mathrm{j}_{\text {th }}$ viewpoint; $d_{\mathrm{j}}$ is the pertinent distance of constant visibility for the $-\mathrm{j}_{\mathrm{th}}$ viewpoint.

The application of Equation 7 to the case study under investigation resulted in a global impact level $L V I$ of $47,9 \mathrm{~dB}$ for case a and 49,3 dB for case b.

Aside from the results found in that specific case, the estimation of a global impact factor $L V I$ can be useful when comparing the quality of different routes with different characteristics of visual impacts or different degrees of naturalness.

\subsection{Landscape value and number of potential observers}

In order to assess the visual impact of those landscape modifications which may be perceived as detrimental by potential observers, it's quite important to define the quality of the territory under investigation, as well as the number and type of people who are likely to observe such modifications.

With specific reference to the assessment method described here, the future development of the research will be the definition of the weighting factors to be applied to the level of visual impact Lvi to account for those aspects and therefore allow the comparison of landscape alterations at different locations.

As regards the quality of the landscape, in particular, the following parameters will be taken into consideration: the provisions of territorial and urban plans, the presence of protected areas (EU Sites of Interest, Natural Parks and Natural Monuments, Archeological sites, etc.), the proximity of touristic destinations, the actual or the potential use of the surrounding territory, the immediacy of industrial sites or other anthropic installations which may have already jeopardized the quality of the area under investigation, etc.

To account for the number and type of potential observers, the subsequent aspects will be considered: the number and type of settlements within short dis- 
tances, the population density of those settlements, the number and type of roads from which the landscape modification is visible, the number of vehicles per day which drive along those roads, etc.

\subsection{Definition of threshold limit values}

A further step to be included in the impact assessment procedure is the impact evaluation; i.e.: the comparison of the estimate impact level ( $L v i$ in this case) against one or more threshold limit values.

The issue had been taken into consideration by the early EU decision 272/02 (Commission Decision, 2002), which established the ecological criteria for the award of the Community eco-label for hard floor-coverings. With reference to a number of environmental impact parameters described in the EU Decision, 4 classes of visual impact were defined: excellent, good, sufficient and exclusion hurdle.

In particular, two parameters among others were indicated in the Decision to account for the impact due to surface excavation: the Rehabilitation Simultaneity Degree, defined as the ratio of the excavated area to the surface of the authorized area, and the Visual Impact Indicator, described by equation (8):

$$
x=\frac{h^{2}}{\left(L \cdot \tan 30^{\circ}\right)^{2}} \cdot 100
$$

where $30^{\circ}$ is the average angle of the human eye vision cone, $h^{2}$ approximates the base surface of the visibility cone of the compromised area, $\left(L \cdot \tan 30^{\circ}\right)^{2}$ approximates the base area of the average visual cone of the human eye.

It's worth noting that a recent revision of the EU decision (Commission Decision, 2009) has changed the name of the Rehabilitation Simultaneity Degree into Quarry impact ratio and abolished the Visual Impact Indicator $(x)$.

The threshold limit values established by the early EU decision 272/02 for the indicator $\mathrm{x}$ are reported in Table 3, together with the corresponding limit values $L v$ calculated according to Equation (3). In particular, the threshold limit values of $L v$ correspond to the limits of the evaluation classes indicated by the European Decision when square-shaped quarries are taken into account (i.e. when the aspect ratio $w / h$ is equal to 1 , where $w$ is the visible quarry width and $h$ is the visible quarry height), in the hypothesis of a chromatic contrast $\Delta E_{\mu}=\Delta E_{\mathrm{BW}}$.

Table 2. Evaluation classes according to the EU decision (Dentoni \& Massacci 2013)

\begin{tabular}{ccccc}
\hline Score & excellent & good & sufficient & $\begin{array}{c}\text { exclusion } \\
\text { hurdle }\end{array}$ \\
\hline$x(\%)$ & $0-10$ & $10-20$ & $20-30$ & $>30$ \\
\hline$L v(\mathrm{~dB})$ & $0-59$ & $58,9-58,8$ & $58,8-60,4$ & $>60,4$ \\
\hline
\end{tabular}

According to the class limits reported in Table 2, all the quarries and mines investigated in previous studies ( $L v i$ in the range $25,6 \div 53,5 \mathrm{~dB}$ ) should be in the excellent class; that appears quite inappropriate and suggests a more accurate definition of the evaluation classes in accordance with the results discuss in paragraph 2, regarding the correlation between Lvi and the actual perception of potential observers.

\section{CORRELATION BETWEEN Lvi AND OBSERVERS' PERCEPTION}

\subsection{Assessment of visual quality: direct and indirect methods}

The evaluation criteria typically applied to assess landscape visual quality are classified into two categories: direct and indirect methods (Shafer 1969, Briggs and France 1979). The first method consists in checking the landscape quality through a single straight step, for example, by means of a customary investigation on visual perception involving potential observers; the second method attempts to indirectly assess the landscape quality by measuring a number of landscape components.

Currently, the prevailing tendency is based on the application of psychophysical models, where direct and indirect criteria are integrated. The psychophysical approach allows the definition of a regression model between the value judgments expressed by a sample of observers and a number of objective variables measured on the landscape under investigation (Shafer et al. 1969).

The use of photographic images to assess the quality of a given landscape has proven to be satisfactory when compared with the perception of the observers expressed directly on site (Shuttleworth 1980). This image-measurement approach is nowadays evolving towards the use of $3 \mathrm{D}$ models for visual analysis of the landscape (Bishop 2003).

\subsection{Perception test}

In a previous study, the correlation between the visual impact indicator $L v i$ and the actual perception of potential observers has been investigated (Dentoni \& Massacci 2007). Following a psychophysical approach, 10 pictures containing opencast quarries or mines were submitted to two samples of students of the University of Cagliari. Sample 1 included students of the Environmental and Land Engineering course, in this case the interviewees could be considered in some measure experts or at least sensitive to environmental protection issues. Sample 2 was composed of arts students (literature, history, philosophy, psychology, foreign languages) and therefore used as a control group, considering that the interviewees probably had the same sensitivity to the issue as any other generic university student. 
The perception test was performed according to the Thurstone scaling procedure (Oppenheim 1992): to each interviewee a set of 10 pictures was shown in a random order together with a brief containing the answering instructions and the final aim of the test. The interviewees were asked to rapidly examine all the pictures and then pick the two corresponding to the minimum and maximum visual impact perception (score 1 and 10 respectively). The interviewees could then associate a score between 1 and 10 to the other 8 photos, without any particular constraint in the choice.

From the same pictures submitted to the 2 samples of students, the geometric extent and the chromatic contrast arising from the quarries were calculated in order to determine the visual impact level $L v i$, according to the method described above. The visual impact parameters and the $L v i$ values for the 10 cases under investigation are reported in Table 3, where each quarry is identified by a conventional abbreviation. The chromatic contrast $\Delta E_{\mu} / \Delta E_{B W}$ was estimated with reference to the CIE Lab color system.

Table 3. Visual impact parameters and the Lvi indicator for the 10 quarries under investigation (Dentoni \& Massacci 2007)

\begin{tabular}{cccc}
\hline Quarry & $\Omega \mathrm{v}[\mathrm{sr}]$ & $\Delta E \mu / \Delta E B W$ & Lvi $[\mathrm{dB}]$ \\
\hline TE & 0,31 & 0,100 & 25,6 \\
CO & 1,05 & 0,066 & 29,1 \\
TR & 1,99 & 0,067 & 32,0 \\
MO & 5,59 & 0,132 & 39,4 \\
NU & 5,80 & 0,155 & 40,3 \\
FO & 7,08 & 0,281 & 43,7 \\
SA & 16,25 & 0,295 & 47,5 \\
SE & 17,14 & 0,277 & 47,5 \\
FL & 20,68 & 0,343 & 49,2 \\
SI & 49,12 & 0,384 & 53,5 \\
\hline
\end{tabular}

\subsection{Test results}

Table 4 shows the parameters of the frequency distributions of the scores given to each of the 10 quarries by the two samples: $S_{50}$ and $S_{75}-S_{25}$ are respectively the median and interquartile range.

Table 4. Frequency distributions of the scores given to each of the 10 quarries by the two samples (Dentoni \& Massacci 2007)

\begin{tabular}{ccccc}
\hline \multirow{2}{*}{ Quarry } & \multicolumn{2}{c}{ Sample 1} & \multicolumn{2}{c}{ Sample 2} \\
\cline { 2 - 5 } & $S_{50}$ & $S_{75}-S_{25}$ & $S_{50}$ & $S_{75}-S_{25}$ \\
\hline TE & 1,43 & 2,10 & 1,00 & 1,20 \\
CO & 1,07 & 0,65 & 1,67 & 1,50 \\
TR & 4,30 & 1,58 & 3,62 & 1,30 \\
MO & 5,57 & 1,36 & 6,00 & 1,82 \\
NU & 5,38 & 1,19 & 5,00 & 1,87 \\
FO & 5,00 & 1,69 & 6,21 & 1,56 \\
SA & 5,90 & 1,46 & 5,40 & 2,40 \\
SE & 7,70 & 1,34 & 7,50 & 2,16 \\
FL & 9,28 & 0,54 & 9,27 & 0,57 \\
SI & 7,73 & 1,34 & 7,09 & 2,98 \\
\hline
\end{tabular}

Table 5 summarizes the results obtained when checking the linear correlations between the median of the scores $S_{50}$ resulting from the perception test and the parameters $\Omega_{\mathrm{v}}, \Delta E_{\mu} / \Delta E_{B W}$ and $L v i$.

For both samples $S_{50}$ proved to be quite well correlated with $\Omega_{\mathrm{v}}$ and with the product $\Omega_{\mathrm{v}} \cdot \Delta E_{\mu} / \Delta E_{B W}$. Better correlations were found with the chromatic contrast $\Delta E_{\mu} / \Delta E_{B W}$ and especially with the indicator Lvi. In the latter case a correlation coefficient of about $91 \%$ was found for both samples.

Table 5. Linear correlation results (Dentoni \& Massacci 2007)

\begin{tabular}{cccc}
\hline Independent vari- & Dependent & \multicolumn{2}{c}{ Correlation coefficient $\mathrm{r}$} \\
\cline { 3 - 4 } able & variable & Sample 1 & Sample 2 \\
\hline$\Omega \mathrm{v}[\mathrm{sr}]$ & $\mathrm{S} 50$ & 0,691 & 0,622 \\
$\Delta E \mu / \Delta E_{B W}$ & $\mathrm{~S} 50$ & 0,818 & 0,820 \\
$\Omega \mathrm{v} \cdot \Delta E \mu / \Delta E_{B W}[\mathrm{sr}]$ & $\mathrm{S} 50$ & 0,629 & 0,560 \\
$L v i[\mathrm{~dB}]$ & $\mathrm{S} 50$ & 0,913 & 0,909 \\
\hline
\end{tabular}

A linear regression analysis between $S_{50}$ and $L v i$ was therefore performed, obtaining the results shown in table 6 .

Table 6. Results of linear regression analysis $S_{50}=a+b \cdot L v i$ (Dentoni \& Massacci 2007)

\begin{tabular}{cccc}
\hline Sample & $a$ & $b$ & $r$ \\
\hline 1 & $-5,163$ & 0,257 & 0,913 \\
2 & $-5,005$ & 0,252 & 0,909 \\
$1+2$ & $-5,084$ & 0,255 & 0,911 \\
\hline
\end{tabular}

\section{VARIABILITY OF THE RESULTS AND CRITICAL ASPECTS}

In previous research work a number of critical aspects, influencing the variability of the results, have been investigated.

Color errors of digital cameras are quite low: 10 CIE Lab $\Delta E$ units on average, i.e. $10 \%$ when divided by $\Delta E_{\mathrm{BW}}$ (Orava et al. 2004). The global variability of $\Delta E_{\mu}$ for a surface excavation is typically higher (up to $33 \%$ ), as it also depends on the variability of the chromatic characteristics of the elements included in the comparison surface (Dentoni \& Massacci 2008; Dentoni et al. 2008).

The precision in the $\Omega_{\mathrm{v}}$ evaluation increases with the number of pixels included in the quarry surface, which depends on the photo resolution and on the focal length used to take the picture, as well as on the distance between the quarry and the viewpoint (Dentoni et al. 2008). The variability of $\Omega_{\mathrm{v}}$ is generally smaller than that of $\Delta E_{\mu}$ : in most cases it is comprised between $3 \%$ and $10 \%$ (Dentoni \& Massacci 2008).

Taking into account the compensation of differences in $\Delta E_{\mu}$ and $\Omega_{v}$, sometimes wide but with opposite sign, the variability of $L v i$ values are modest, at most $1.1 \mathrm{~dB}$ (Dentoni \& Massacci 2008). 
Where the vegetation is made up by broad-leaved deciduous trees the chromatic contrast in spring or summer can be higher by about $50 \%$ (as an order of magnitude) if compared with the winter season, provided that the air transparency is comparable (Dentoni et al. 2008).

The chromatic contrast regularly decreases with increasing distances due to the atmospheric scattering. This reduction contributes to the overall reduction of $L v i$ for a value between $0.5 \mathrm{~dB}$ and $0.9 \mathrm{~dB}$ with each doubling of the distance when good visibility conditions are considered (Dentoni \& Massacci 2008).

\section{CONCLUSIONS}

The article summarizes the results of the application of the Lvi method to a variety of quarries and mines located in Europe and discusses the adequacy of the method in providing an objective estimation of the visual damage produced by surface excavation.

The Lvi method is based on the elaboration of digital images, taken from the most representative viewpoints around the mining areas (public roads, towns, villages, touristic sites, etc.), which provide both the solid angle subtended by the altered area from a given observation point and the chromatic contrast of the bare rock with a comparison surface representing the dominant colors of the surrounding landscape.

The results of previous studies discussed in this article also show the possibility of calculating a global impact factor $L V I$ to be associated with a given route, in order to account for the variability of the visual impact with the curvilinear abscissa of the route itself.

Future developments of the research will include the definition of the weighting factors to be applied to the level of visual impact $L v i$, to allow for the number of potential observers and the quality of the landscape; this last aspect could easily be estimated on the basis of objective parameters, such as the provisions of territorial and urban plans and the presence of protected areas within a certain distance.

An additional aspect to be looked into more depth is the definition of the evaluation classes in accordance to the actual perception of potential observers. In fact, a recent research proved the subjective visual impact perception determined by surface excavation (measured by the median of the judgement values expressed by a group of interviewees) to be significantly correlated with the visual impact indicator Lvi.

\section{REFERENCES}

Bishop, I.D. 1997. Testing perceived landscape colour difference using the Internet. Landscape and Urban Planning, 37(3-4): 187-196.

Bishop, I.D 2003. Assessment of visual qualities, impacts, behaviours, in the landscape, by using measures of visibility.
Environment and Planning B: Planning and Design, 30: 677-688.

Briggs, D.J. \& France, J. 1980. Landscape Evaluation: A comparative study. Journal of Environmental Management, 1980, 10: 263-275.

Commission Decision 2002/272/EC of 25 March 2002 establishing the ecological criteria for the award of the Community eco-label to hard floor-coverings. OJ No L 94, 11.04.2002: 13-27.

Commission Decision 2009/607/EC of 9 March 2009 establishing the ecological criteria for the award of the Community eco-label to hard coverings. OJ No L 208, 12.08.2009: 2138.

Dentoni, V., Massacci, G. \& Meloni, R. 2004. Landscape and Visual Impact Assessment of Opencast Mining. In A.G. Pasamehmetoglu, A. Ozgenoglu \& A.Y. Yesilay (Eds.), Proc. of the 8th International Symposium on Environmental Issues and Waste Management in Energy and Mineral Production (SWEMP 2004), Antalya, Turkey, 17th-20th May 2004: 113-118. Atilim University, Ankara. ISBN 975-670711-9.

Dentoni, V., Massacci, G. \& Radwanek-Bąk, B. 2006. Visual impact of quarrying in the Polish Carpathians. Geological Quarterly, 2006, 50(3): 383-390. Polish Geological Institute, Warsaw, ISSN 1641-7291.

Dentoni, V. \& Massacci, G. 2007. Visibility of Surface Mining and Impact Perception. International Journal of Mining, Reclamation and Environment, 2007, 21(1): 6-13.Taylor \& Francis, ISSN 1748-0930 print, ISSN 1748-0949 online.

Dentoni, V. \& Massacci, G. 2008. Visibility of surface excavation and impact assessment. In Proc. of the $2^{\text {nd }}$ International Workshop in Geoenvironment and Geotechnics (GEOENV 2008), Milos island, Greece, 8th-9th September 2008: 157-162. Heliotopos Conferences, Athens. ISBN 978-960-6746-01-7

Dentoni, V., Massacci, G. \& Radwanek-Bąk, B.D. 2008. Visual Impact of Surface Mining and Quarrying. In Proc. of the XXI World Mining Congress, Kraków, Poland, 7th-11th September 2008: 49-60. Drukarnia Patria, Kraków. ISBN 978-83-88519-82-6.

Dentoni V. \& Massacci G. 2012. Assessment of Visual Impact Generated by Surface Excavation. In Proc. of the 21st International Symposium on Mine Planning \& Equipment Selection (MPES 2012), New Delhi, India, November 28-30, 2012: 173-183. CD ROM published by The Reading Matrix Inc., Irvine, CA, USA. R. K. Singhal, E. Topas, K. Fytas, M. Yellishetty, Mehrotra, eds. ISSN 2167-3322.

Dentoni, V. \& Massacci, G. 2013. Assessment of visual impact induced by surface mining with reference to a case study located in Sardinia (Italy), Environ Earth Sci 68:14851493, ISSN 1866-6280. DOI 10.1007/s12665-012-1994-3.

Menegaki, M., Koutiva, I. \& Kaliampakos, D. 2014 Assessing the chromatic contrast in open surface excavations: a comparative study between subjective and quantitative approaches. International Journal of Mining, Reclamation and Environment, DOI:10.1080/17480930.2013.866791.

Nicholson, D.T. 1995. The Visual Impact of Quarrying. Quarry Management, 22(7): 39-42.

Oppenheim, A.N. 1992. Questionnaire design, interviewing and attitude measurement, 303 pp., London and New York: Continuum.

Orava, J., Jaaskelainen, T. \& Parkkinen, J. (2004). Color errors of digital cameras. Color research and application 29(3): 217-221.

Pinzari, M. \& Re, P. 1990. L'angolo solido di visione e sua utilizzazione nella redazione automatica della cartografia tecnica dell'impatto paesaggistico di cave e grandi opere all'aperto. In Proc. I Convegno Minerario Italo-Brasiliano Cagliari, A. Trois: 9-19 (in Italian). 
Shafer, E.L. 1969. Perception of natural environments. Environment and Behavior, 1: 71-82.

Shafer, E.L., Hamilton, J.F. \& Schmidt, E.A. 1969 Natural landscape preferences: a predictive model. Journal of Leisure Research, 1: 1-19.

Shuttleworth, S. 1980. The Use of Photographs as an Environmental Presentation Medium in Landscape Studies. Journal of Environmental Management, 11: 61-76.

Sklenicka, P. \& Molnarova, K. 2010. Visual perception of habitats adopted for post-mining landscape rehabilitation, Environmental Management, 46: 424-435.

Svobodova K., Sklenicka P., Molnarova K. \& Salek M. 2012.Visual preferences for physical attributes of mining and post-mining landscapes with respect to the sociodemographic characteristics of respondents, Ecological Engineering, 43: 34-44.

\section{ACKNOWLEDGEMENTS}

Investigation carried out in the framework of projects conducted by IGAG - CNR (Environmental Geology and Geoengineering Institute of the National Research Council), Cagliari, Italy, and by CINIGeo (National Inter-university Consortium for Georesources Engineering, Rome, Italy). 